\title{
Development of an Air-Purification Unit Using a Photocatalysis-Plasma Hybrid Reactor
}

\author{
Tsuyoshi OchiaI, ${ }^{\mathrm{a}, \mathrm{b}, *}$ Kazuya Nakata, ${ }^{\mathrm{a}, \mathrm{b}}$ Taketoshi Murakami, ${ }^{\mathrm{a}}$ Yuko Morito, ${ }^{\mathrm{b}, \mathrm{c}}$ \\ Shunsuke Hosokawa, ${ }^{d}$ and Akira FujISHIma ${ }^{a, b}$
}

\begin{abstract}
${ }^{a}$ Kanagawa Academy of Science and Technology (3-2-1 Sakado, Takatsu-ku, Kawasaki, Kanagawa 213-0012, Japan)
${ }^{b}$ Division of Photocatalyst for Energy and Environment (Research Institute for Science and Technology, Tokyo University of Science, 1-3 Kagurazaka, Shinjuku-ku, Tokyo 162-8601, Japan)

${ }^{c}$ U-VIX Corporation (2-14-8 Midorigaoka, Meguro-ku, Tokyo 152-0034, Japan)

${ }^{\mathrm{d}}$ Masuda Research Inc. (Kaneyasu Bld. 6F, 2-40-11, Hongo, Bunkyo-ku, Tokyo 113-0033, Japan)
\end{abstract}

Received March 27, 2011 ; Accepted May 10, 2011

\begin{abstract}
The novel photocatalysis-plasma hybrid air-purification unit using a titanium-mesh sheet modified $\mathrm{with}^{\mathrm{TiO}} \mathrm{O}_{2}$ $\left(\mathrm{TMiP}^{\mathrm{TM}}\right)$ and a surface discharge-induced plasma (SPCP) was investigated. The SPCP unit generates air-plasma on wide area of its surface and TMiP sheet was successfully irradiated by air-plasma without any destruction. Significant decomposition of the ammonia gas has been achieved by the photocatalysis-plasma hybrid reactor. In the present experimental condition, the SPCP unit without TMiP and UV-lamp with TMiP was not effective on the decomposition of the ammonia gas. Therefore, synergistic effects of catalytic activation and plasma excitation on the hybrid reactor with large surface area is useful for significant oxidative decomposition of gaseous pollutants.
\end{abstract}

Key Words : Photocatalysis, Titanium Dioxide, Air-Plasma, Air-Purification

\section{Introduction}

Since the discovery of photocatalytic water splitting by $\mathrm{TiO}_{2}$ in 1967 , the strong oxidation ability of $\mathrm{TiO}_{2}$ has received growing attention. ${ }^{1-3)} \mathrm{TiO}_{2}$ generates hydroxyl radicals and superoxide ions by UV light irradiation. These are highly reactive with organic compounds. Moreover, when $\mathrm{TiO}_{2}$ is exposed to light, its surface exhibits superhydrophilicity, with water contact angles of $5^{\circ}$ or less. ${ }^{4)}$ The combination of these oxidative decomposition and superhydrophilicity leads to maintain the original clean state of the $\mathrm{TiO}_{2}$ surface. Thus, $\mathrm{TiO}_{2}$ photocatalysts are mainly applied to exterior materials such as windows, mirrors, and building materials now. Recently, environmental contaminations become serious problems in the world. The strong oxidation ability of $\mathrm{TiO}_{2}$ is expected to resolve these problems. However, there are several limitations such as electron-hole recombination, low efficiency, and difficulty in decomposition of large amount of pollutants. Therefore, the market of photocatalytic air purifier or water purifier does not have large share such as that of exterior materials. On the other hand, nonthermal plasma treatment is able to decompose gaseous pollutants efficiently.-8) Moreover, nonthermal plasma in air produces UV light due to the transitions of excited nitrogen molecules. ${ }^{9,10}$ There are several reports about combination of nonthermal plasma and $\mathrm{TiO}_{2}$ photocatalysts to decompose organics. ${ }^{10-16)}$ However, these results indicate that the contribution of photocatalysis induced by UV light from the nonthermal plasma was not significant.

In the present work, highly ordered three dimensional titanium mesh impregnated $\mathrm{TiO}_{2}$ nanoparticles $\left(\mathrm{TMiP}^{\mathrm{TM}}\right)$ and surface discharge-induced plasma (SPCP) unit were successfully combined as novel plasma-photocatalyst hybrid reactor. TMiP provides excellent air pass through while maintaining a high level of surface contact. The SPCP unit makes air-plasma with high intensity and large irradiation area. Air purification efficiency of the reactor was examined by high concentration ammonia decomposition.

\subsection{Fabrication of $\mathrm{TMiP}^{17)}$}

\section{Experimental}

The method for fabrication of TMiP is shown in Fig. 1. The Ti-mesh, obtained by controlled chemical etching of titanium foil with a $0.2 \mathrm{~mm}$ thickness, was anodized at a voltage of $70 \mathrm{~V}$ for violet color in acid solution. The resulting structure could be controlled by mask pattern and etching time as shown in Fig. 1 and the colors could be controlled by anodizing voltage and time. Then the Ti-mesh was treated at $500^{\circ} \mathrm{C}$ for $3 \mathrm{~h}$ to make $\mathrm{TiO}_{2}$ layer on the Ti-mesh surface. Treated Ti-mesh was dip-coated with $25 \mathrm{wt} \%$ of $\mathrm{TiO}_{2}$ anatase sol (TKD-701, TAYCA) and was heated at $500^{\circ} \mathrm{C}$ for $3 \mathrm{~h}$. Its structural and surface morphology of TMiP were examined and studied using X-ray diffraction (XRD) and Scanning Electron Microscopy (SEM).

\subsection{Power supply}

A commercial electric power line of $50 \mathrm{~Hz}$ and $100 \mathrm{~V}$ was connected through a power supply (IP II, Masuda Research Inc.) as shown in Fig. 2. We used a voltage of $8.96 \mathrm{p}-\mathrm{pkV}$, a frequency of $8.45 \mathrm{kHz}$, and a power of $40 \mathrm{~W}$. 2.3 Photocatalysis-plasma hybrid reactor

A photocatalysis-plasma hybrid reactor shown in Fig. 

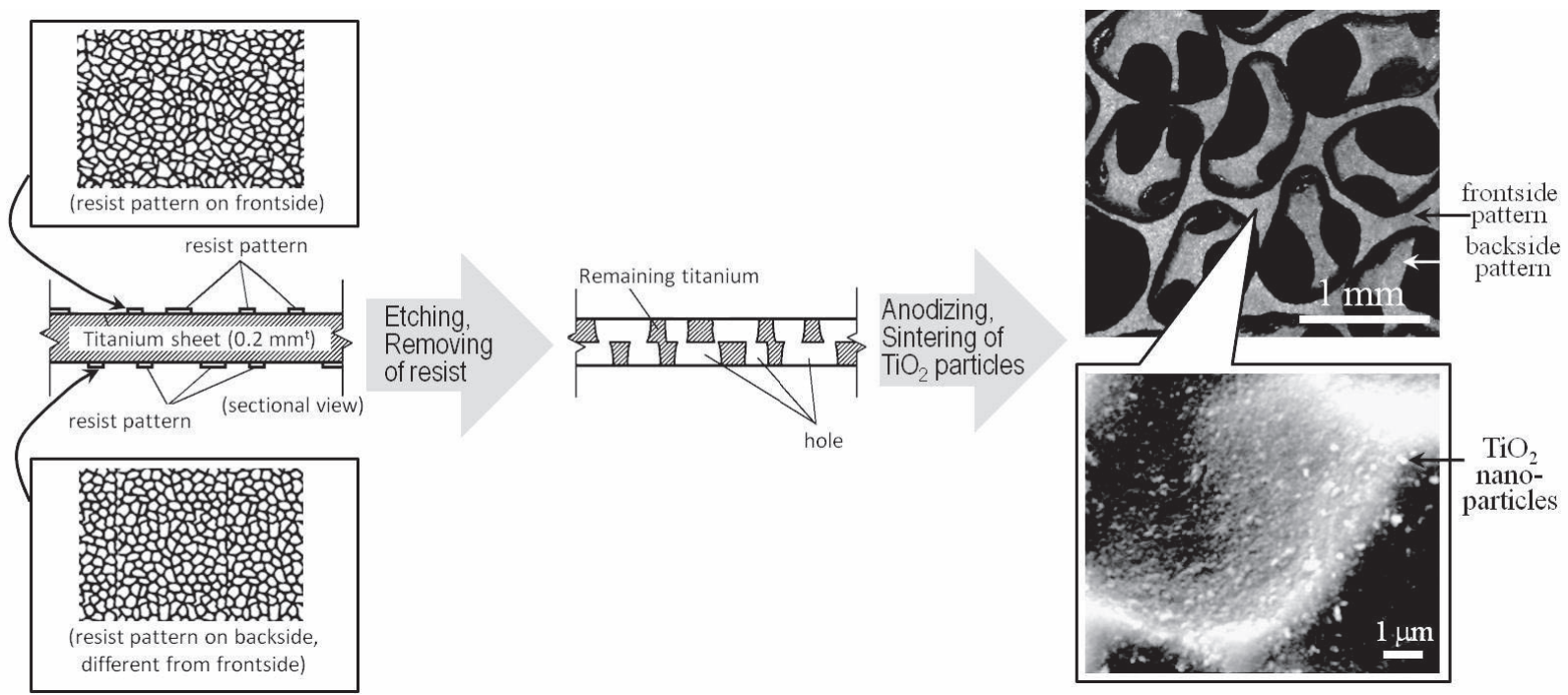

Fig. 1 The method for fabrication of titanium-mesh sheet with highly ordered three-dimensional structure modified with $\mathrm{TiO}_{2}$ nanoparticles.

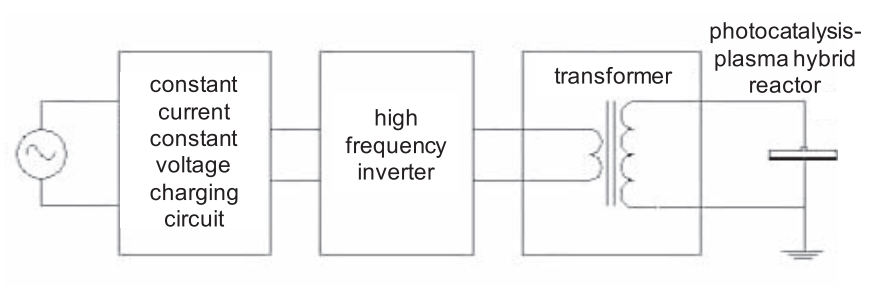

Fig. 2 Schematics diagram of electronic circuit.

(a)

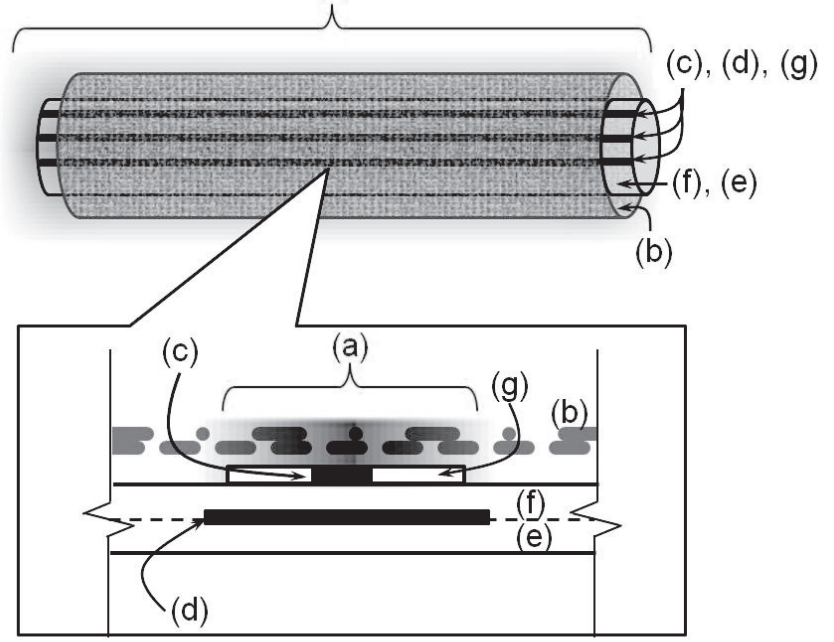

Fig. 3 The schematic view (upper) and sectional view (lower) of photocatalysis-plasma hybrid reactor. (a) plasma, (b) TMiP, (c) discharge electrode, (d) induction electrode, (e) alumina ceramic tube, (f) dielectric (almina), (g) alumina coating.

3 consists of SPCP unit (OC-002, Masuda Research Inc.) ) $^{8)}$ and TMiP. In SPCP unit, the induction electrode plate is embedded in the alumina ceramic tube wall and the stripe-like discharge electrode is fixed on the surface of the ceramic tube with alumina coating. The SPCP unit

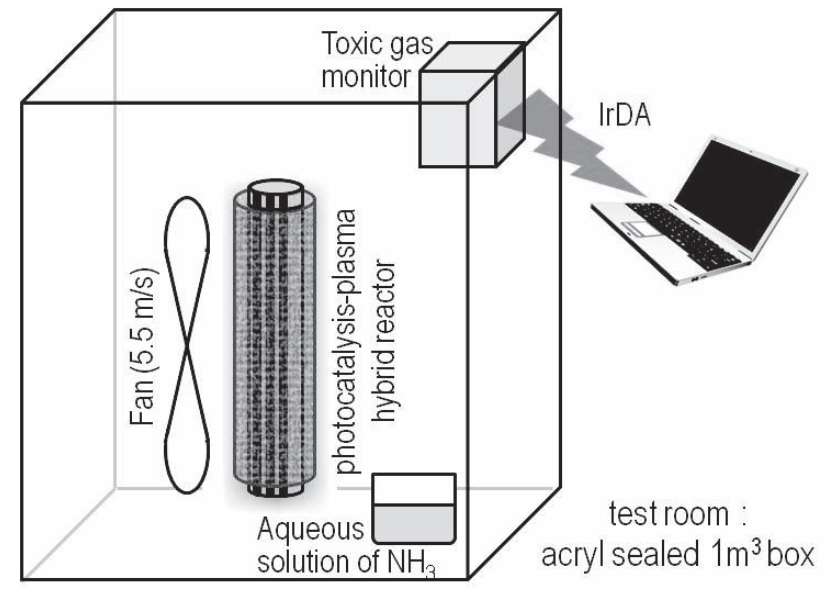

Fig. 4 Schematic illustration of gas decomposition test.

was wrapped by TMiP sheet connected to ground. If the AC high voltage is applied between two electrodes, the discharge occurs on the ceramic surface which is named as the surface discharge. For the photocatalysis-plasma hybrid reactor, $\mathrm{kHz}$ high frequency high voltage is used but for the nonthermal plasma generation.

\subsection{Total system of ammonia decomposition test}

A schematic diagram of a total experimental system used for gas decomposition is shown in Fig. 4. The photocatalysis-plasma hybrid reactor and fan placed inside the test room (acryl sealed $1 \mathrm{~m}^{3}$ box). Air was blown on the reactor continuously, and ammonia gas was evaporated from $30 \mathrm{~mL}$ of aqueous solution of ammonia (1\%) in a beaker. Time course of the concentration of ammonia was monitored by a Single Toxic Gas Monitor (Riken Keiki Instruments: SC-01 with a electrochemical sensor for Ammonia). For comparison, the SPCP unit without TMiP (air-plasma-only) and 18W UV-lamp (ZW18D15YZ356, Cnlight) with TMiP (UV-lamp-photocatalysis) were also examined. The experiments were carried out at room temperature and atmospheric pressure. 


\subsection{Plasma generation}

\section{Results and Discussion}

Figure 5 shows the overview of the photocatalysisplasma hybrid reactor. After plasma generation, strong purple luminescence of air-plasma was observed by the naked eye on the SPCP unit. The TMiP on the SPCP surface was successfully irradiated by purple air-plasma without any destruction.

\subsection{Spectral analysis}

Figure 6 shows the spectra for the emission from the UV lamp, the air-plasma, and the absorptions of TMiP. Under present conditions, the UV lamp emitted mainly 250-450 nm light (Fig. 6, bloken line) originating from excited species of mercury. The air-plasma emitted mainly 300-400 nm light (Fig. 6, solid line) originating from excited species of nitrogen.1.16) On the other hand, due to the wide band-gap of anatase $\mathrm{TiO}_{2}$ photocatalysts $(3.2$ $\mathrm{eV})$, TMiP mainly absorbs ultraviolet photons with the wavelength of less than $387 \mathrm{~nm}$ (Fig. 6, dotted line). ${ }^{3)}$ Therefore, emissions from the UV lamp and air plasma

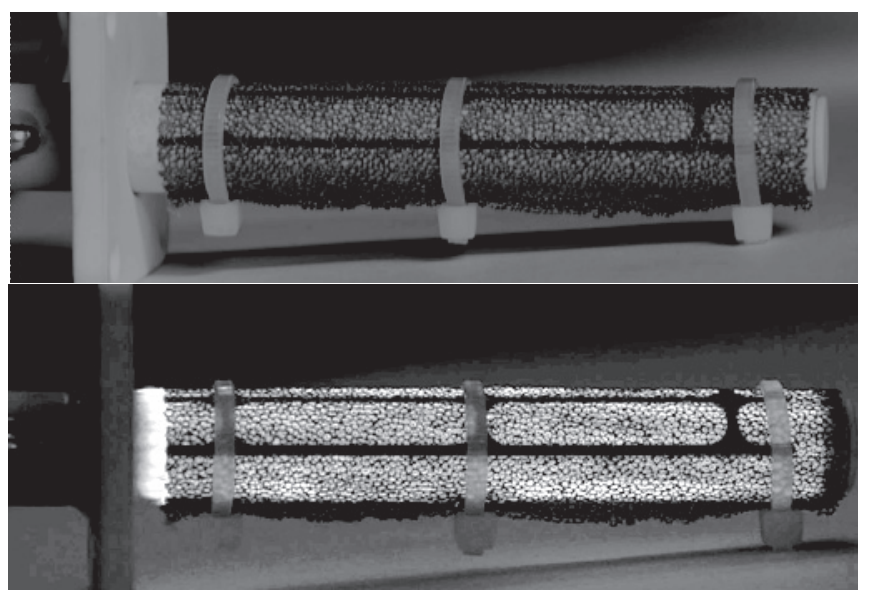

Fig. 5 The overview of photocatalysis-plasma hybrid reactor with the plasma turned off (upper) and turned on (lower).

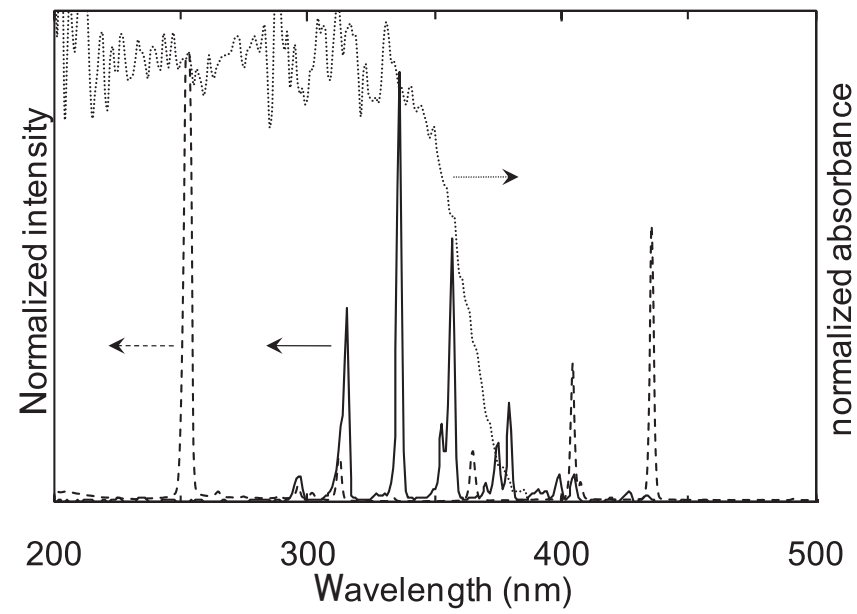

Fig. 6 Spectra for the emission from the UV lamp (bloken line), air-plasma (solid line), and the absorptions of TMiP (dotted line). are in the range of the band gap of the $\mathrm{TiO}_{2}$ catalyst on TMiP surface. The UV intensities of UV lamp and airplasma measured by the UV power meter (Hamamatsu Photonics, C9536/H9535-254 and C9536-01/H9958) were $15 \mathrm{~mW} / \mathrm{cm}^{2}(254 \mathrm{~nm})$ and $0.01 \mathrm{~mW} / \mathrm{cm}^{2}(310-380 \mathrm{~nm})$, respectively. The photon flux densities of UV lamp and air-plasma calculated from the UV intensities were 0.13 and $8.4 \times 10^{-5} \mathrm{~mol} \mathrm{~cm}^{-2} \mathrm{~s}^{-1}$, respectively.

\subsection{Ammonia decomposition}

Figure 7 shows the time course of $\mathrm{NH}_{3}$ concentration in test box. Under these conditions without any reactor (Fig. 7, crosses), the concentration increased greatly by evaporation of $\mathrm{NH}_{3}$ from the solution. After 8 minutes, $\mathrm{NH}_{3}$ concentration reached $24 \mathrm{ppm}$. This value is higher than the upper permissible limit of $\mathrm{NH}_{3}(20 \mathrm{ppm})$ in animal barns. However, animals are exposed chronically to atmospheric $\mathrm{NH}_{3}$ at concentrations that may exceed 30 ppm in animal barns with poor environmental control. ${ }^{18}$ Thus, the present experimental condition is suitable for evaluation of the air-purification ability of the reactor in highly contaminated environment such as animal barn.

With air-plasma-only (Fig. 7, open circles), $\mathrm{NH}_{3}$ concentration gradually increased with almost a half speed for that without any reactor. Similar result was obtained by UV-lamp-photocatalysis (Fig. 7, filled triangles). These results indicate that $\mathrm{NH}_{3}$ could be decomposed by both air-plasma-only and UV-lamp-photocatalysis. When the $\mathrm{TiO}_{2}$ is irradiated by UV light, excitation of electrons into the conduction band takes place, resulting in formation of holes in the valance band. Both the holes and the electrons migrate to the $\mathrm{TiO}_{2}$ surface, where they either recombine or react with adsorbed species such as $\mathrm{H}_{2} \mathrm{O}$ and $\mathrm{O}_{2}$. The holes oxidize adsorbed $\mathrm{H}_{2} \mathrm{O}$ to $\cdot \mathrm{OH}$, which is the potential oxidant in photocatalysis, whereas the electrons reduce $\mathrm{O}_{2}$ to $\mathrm{O}^{-3}{ }^{-3)}$ There are two possible pathways for the photocatalytic oxidation of $\mathrm{NH}_{3}:{ }^{19)}$

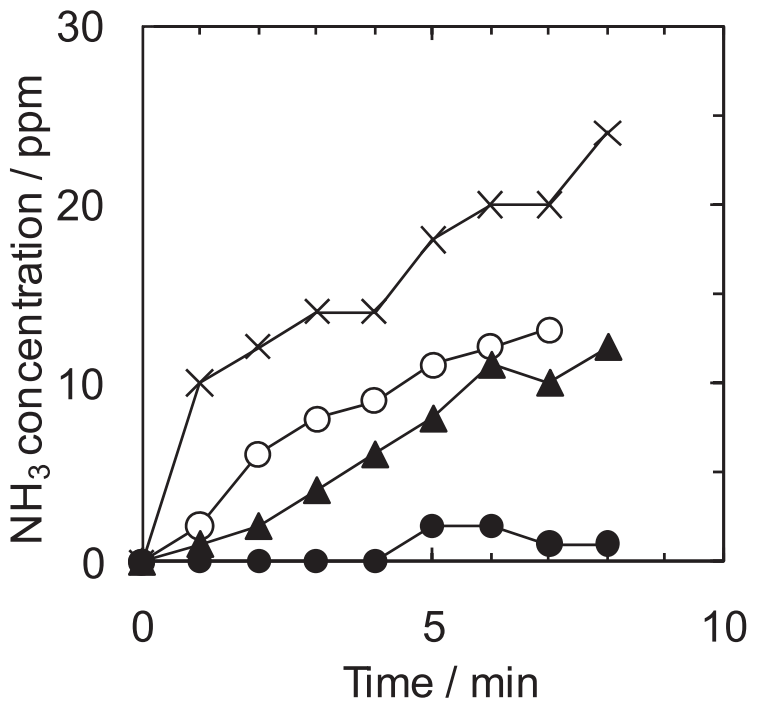

Fig. 7 Time course of $\mathrm{NH}_{3}$ concentration in test box (crosses: blank; open circles: air-plasma-only; filled triangles: UV-lamp-photocatalysis; filled circles: photocatalysisplasma hybrid reactor). The experiments were carried out at room temperature and atmospheric pressure. 


$$
\begin{aligned}
& \mathrm{NH}_{3}+2 \mathrm{H}_{2} \mathrm{O}+6 \mathrm{~h}^{+} \rightarrow \mathrm{NO}_{2}^{-}+7 \mathrm{H}^{+} \\
& \mathrm{NH}_{3}+\mathrm{O}_{2}+2 \mathrm{~h}^{+} \rightarrow \mathrm{NO}_{2}^{-}+3 \mathrm{H}^{+}
\end{aligned}
$$

Finally, $\mathrm{NO}_{2}^{-}$generated by Eq. (1) and/or (2) is further oxidized to $\mathrm{NO}_{3}^{-}$and fixed onto $\mathrm{TiO}_{2}$ surface:

$$
\mathrm{NO}_{2}^{-}+\mathrm{H}_{2} \mathrm{O}+2 \mathrm{~h}^{+} \rightarrow \mathrm{NO}_{3}^{-}+2 \mathrm{H}^{+}
$$

On the other hand, decomposition process of $\mathrm{NH}_{3}$ is not yet clear in air-plasma-only. But reactive species, such as $\mathrm{NO}_{2}, \mathrm{O}_{3}$, and radicals generated by air-plasma play an important role in the decomposition of $\mathrm{NH}_{3}{ }^{6,8)}$ similar to photocatalytic oxidation of $\mathrm{NH}_{3}$. However, the decomposition rates by these reactions were slower than evaporation rate of $\mathrm{NH}_{3}$ from solution. Thus, $\mathrm{NH}_{3}$ concentration gradually increased.

Interestingly, photocatalysis-plasma hybrid reactor almost totally prevented the increase of $\mathrm{NH}_{3}$ concentration (Fig. 7, filled circles). This result indicates that photocatalysis-plasma hybrid reactor could decompose $\mathrm{NH}_{3}$ effectively than air-plasma-only and UV-lamp-photocatalysis. There is an explanation of this result, i.e., the $\mathrm{O}_{3}$ generated by air-plasma decomposes on the TMiP surface and atomic oxygen is produced by catalytic decomposition: ${ }^{15)}$

$$
\mathrm{O}_{3} \rightarrow \mathrm{O}_{2}+\mathrm{O}^{*}
$$

Here the symbol * represents a surface site of $\mathrm{TiO}_{2} . \mathrm{O}^{*}$ is a highly active intermediate formed from $\mathrm{O}_{3}$ catalytic decomposition. ${ }^{20)}$ In the present study, the ozone concentration in the system was about $20 \mathrm{ppm}$ and relative surface area of TMiP was $664 \mathrm{~cm}^{2} / \mathrm{cm}^{2}$ (real surface area/ mathematical surface area). ${ }^{17}$ ) Therefore, the $\mathrm{O}^{*}$ concentration is enough to react with $\mathrm{NH}_{3}$ and oxidize it. Therefore, $\mathrm{O}^{*}$ was the dominant active species in the plasma-photocatalyst hybrid reactor.

\section{Conclusions}

The removal of ammonia using photocatalysis-plasma hybrid reactor was investigated. Much higher efficiency was achieved in the plasma-photocatalyst hybrid reactor, compared with the UV-irradiated photocatalysis or plasma treatment only. This high efficiency is not only resulted from the irradiation of high-energy electrons but also catalytic ozonation. The active oxygen formed from ozone catalytic decomposition may play important role in the plasma-photocatalyst hybrid reactor. Although we used a simple reactor with conventional methods and conditions, for example, atmospheric pressure, it would be attractive to develop a similar continuous-type air purification system for the practical treatment of highly contaminated environment, such as animal barns.

\section{References}

1) A. Fujishima and K. Honda, Nature, 238, 37 (1972).

2) A. Fujishima, T. N. Rao, and D. A. Tryk, J. Photochem. Photobiology C.: Photochem. Rev., 1, 1 (2000).

3) A. Fujishima, X. Zhang, and D. A. Tryk, Surf. Sci. Rep., 63, 515 (2008).

4) R. Wang, K. Hashimoto, A. Fujishima, M. Chikuni, E. Kojima, A. Kitamura, M. Shimohigoshi, and T. Watanabe, Nature, 388, 431 (1997).

5) H. C. Kang, J. Ind. Eng. Chem., 8, 488 (2002).

6) T. Oda, R. Yamashita, T. Takahashi, and S. Masuda, IEEE Trans. Ind. Appl., 32, 227 (1996).

7) T. Oda, T. Takahashi, H. Nakano, and S. Masuda, IEEE Trans. Ind. Appl., 29, 787 (1993).

8) S. Masuda, S. Hosokawa, X. Tu, and Z. Wang, J. Electrost., 34, 415 (1995).

9) N. Spyrou and C. Manassis, J. Phys. D: Appl. Phys., 22, 120 (1989).

10) M. Magureanu, D. Laub, A. Renken, and L. KiwiMinsker, J. Phys. Chem. C., 111, 4315 (2007).

11) A. Ogata, H.-H. Kim, S. Futamura, S. Kushiyama, and K. Mizuno, Appl. Catal. B: Environ., 53, 175 (2004).

12) J. Taranto, D. Frochot, and P. Pichat, Ind. Eng. Chem. Res., 46, 7611 (2007).

13) H. U. Lee, K. Ahn, S. Y. Jeong, C. R. Cho, J. P. Kim, J. S. Bae, H. G. Kim, S. H. Kwon, and H. W. Lee, Appl. Phys. Lett., 97, 223111-1 (2010).

14) Z. P. Yao, F. Z. Jia, S. J. Tian, C. X. Li, Z. H. Jiang, and X. F. Bai, ACS Appl. Mater. Interfaces, 2, 2617 (2010).

15) H. B. Huang, D. Q. Ye, and D. Y. C. Leung, J. Environ. Eng. ASCE, 136, 1231 (2010).

16) H.-H. Kim, Y.-H. Lee, A. Ogata, and S. Futamura, Catal. Commun., 4, 347 (2003).

17) T. Ochiai, T. Hoshi, H. Slimen, K. Nakata, T. Murakami, H. Tatejima, Y. Koide, A. Houas, T. Horie, Y. Morito, and A. Fujishima, Catal. Sci. Technol., accepted, DOI:10.1039/C1CY00185J (2011).

18) B. Kavolelis, Pol. J. Environ. Stud., 12, 709 (2003).

19) C. H. Pollema, E. B. Milosavljević, J. L. Hendrix, L. Solujić, and J. H. Nelson, Monatsh. Chem./Chem. Mon., 123, 333 (1992).

20) H. Einaga and S. Futamura, J. Catal., 227, 304 (2004). 